\title{
Keiichiro Yoshinaga, MD, PhD, FACC, FASNC
}

On October 7, 2020, Dr Keiichiro Yoshinaga passed away due to advanced gastric cancer. His contributions to nuclear cardiology and cardiac PET have been significant. His creative inspiration and active spirit will be missed tremendously.
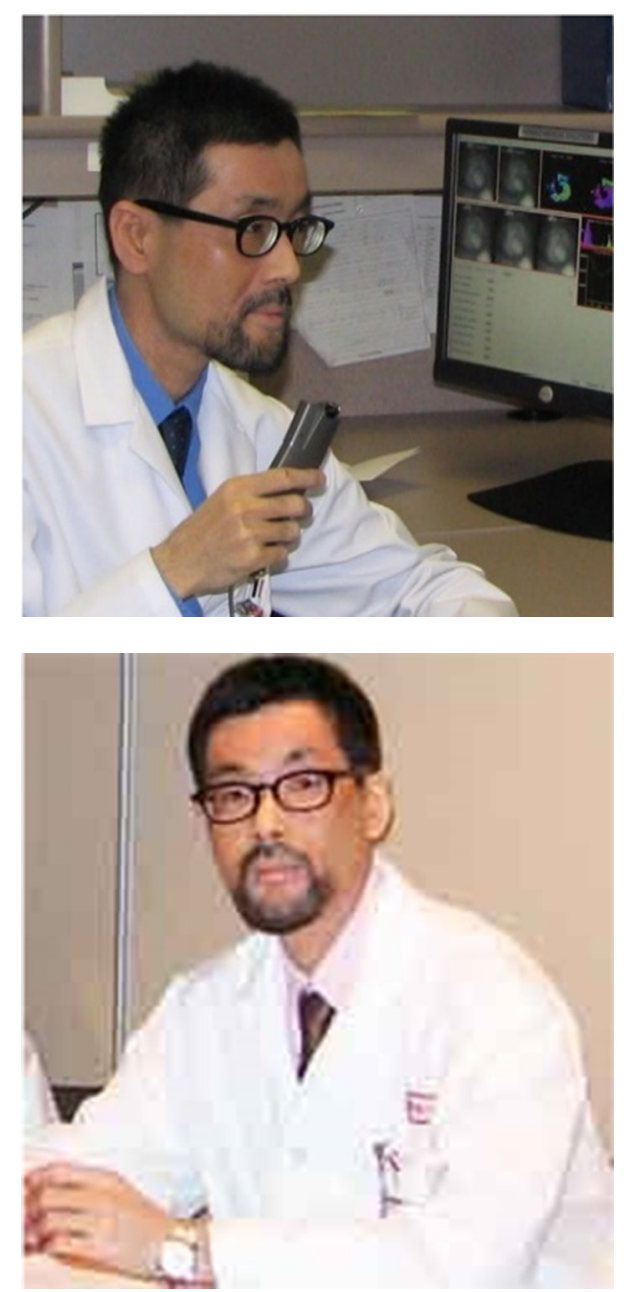

J Nucl Cardiol 2021;28:377-80.

$1071-3581 / \$ 34.00$

Copyright (c) 2020 American Society of Nuclear Cardiology. doi:10.1007/s12350-020-02432-6
He graduated from Kagoshima University Medical School in 1992 and continued his training as a cardiologist, where he was stimulated by nuclear cardiology. Due to his strong desire to learn more in this field, he joined our Nuclear Medicine Department at Hokkaido University as a clinical fellow in 1999. At that time, we had just started our PET and in-house cyclotron project. $\mathrm{He}$ became involved in key projects in quantitative assessment of myocardial blood flow and flow reserve with several young nuclear medicine and cardiology scientists. He actively contributed to the scientific and medical community through several high-impact papers. In addition, he attended international scientific meetings to report and discuss with many scientists at these meetings.

In order to further develop his research expertise, he joined the University of Ottawa Heart Institute (UOHI) as a research fellow in 2003 and stayed there for two and half years. Keiichiro was a highly motivated clinicianscientist who exceled by his determination, resilience, intellect, and kind personality. He led several research projects that he went on to publish in JNC and other leading journals including among the first studies to demonstrate the prognostic value of PET perfusion imaging (JACC 2006) and also the beneficial impact of CPAP therapy in heart failure on cardiac energetics (JACC 2007). He helped in establishing the Molecular Function and Imaging Program at UOHI, setting up regular seminars for the program. Indeed, this was a pivotal time and turning point in Ottawa, whereby Keiichiro was instrumental for UOHI to obtain a large program grant from the Heart and Stroke Foundation of Ontario (Canada) that helped UOHI significantly enhance its imaging research program. This is amazing in itself, but even more so when one considers that he was half a world away from home on a new continent with a foreign language and different culture. Not only did he learn English, he embraced Ottawa, learning its restaurants and cultural attractions. While there, he worked and befriended many known clinicians and scientists. He fostered lifelong collaborations and personal friendships which he commemorated each year with hand-written letters on traditional Japanese art cards. 
After returning to Japan in 2006, he continued to publish important papers in the field of nuclear cardiology and cardiac PET.

His major papers dealing with PET measurements of alteration in myocardial flow reserve, endothelial function, myocardial oxygen extraction, and consumption have had major impact in the field of Nuclear Cardiac imaging and are often cited. In order to promote quantitative measurements, he devoted much time and energy engaging with physicists and basic scientists. I believe such collaboration was the result from his earlier valuable experiences during his fellowship in Canada. $\mathrm{He}$ introduced Rb-82 generators for cardiac PET for the first time in Japan in 2007. With his peers he established a dual spillover correction model for quantitative assessment of myocardial blood flow and flow reserve, and validated it in comparison with O-15 water PET.

$\mathrm{He}$ has recently published several key reviews and editorials in the Journal of Nuclear Cardiology such as:

(1) Coronary endothelial dysfunction, https://link . springer.com/article/10.1007/s12350-011-9370.

(2) Japanese nuclear cardiology activity, https://link. springer.com/article/10.1007/s12350-016-0655-4 and https://link.springer.com/article/10.1007/ s12350-015-0136-1

(3) Absolute quantification of myocardial blood flow, https://link.springer.com/article/10.1007/s12350016-0591-3

(4) Recommendation of FDG-PET for cardiac sarcoidosis, https://link.springer.com/article/10.1007/ s12350-019-01755-3

(5) Ventricular phase analysis, https://link.springer. com/article/10.1007/s12350-020-02216-y

In 2017, he moved to the National Institute of Radiological Science in Chiba where he made his mark on the use of novel radioisotopes for therapy.

One of his remarkable accomplishments is the production of a new journal, Annals of Nuclear Cardiology (ANC) as the official journal of Japanese Society of Nuclear Cardiology and also an important outlet of our field in Asia. He became the Editor-in-Chief and worked hard to publish many papers and editorials by revered researchers from around the world, as many of the readers of JNC have likely experienced his personal invitations. He strove and succeeded in fostering collegial relations with other journals in the field, particularly, the Journal of Nuclear Cardiology, resulting in co-published papers in both journals.

He regularly submitted scientific abstracts to major academic meetings such as ASNC, SNMMI, ACC, and AHA. He enjoyed attending these scientific meetings and looked forward to sharing his new and exciting experiences with his international colleagues.

His friends recall that Keiichiro was a connoisseur of fine foods. Before these meetings he would rigorously research the best restaurants and would organize reunions with his former colleagues. These venues were often out of the way and difficult to attend but always resulted in long evening of lively discussion, exquisite foods, and anticipation for the next reunion.

He was highly engaged with ASNC and the JNC. He established key collaborations between ASNC and the JSNC which led to joint publications between JNC and ANC, joint workshops, and symposia. The ASNCJSNC relationship has been a notable example of international societies working together for common goals. His strong ties to ASNC and its members were exemplified by the tremendous outpouring of heartfelt messages at the shock of untimely death. He was indeed a gentleman and a scholar. ASNC member Tim Christian made the suggestion to "honor him by submitting an original work, a review, or an editorial to ANC" ( https://www.jstage.jst.go.jp/browse/anc/-char/en ).

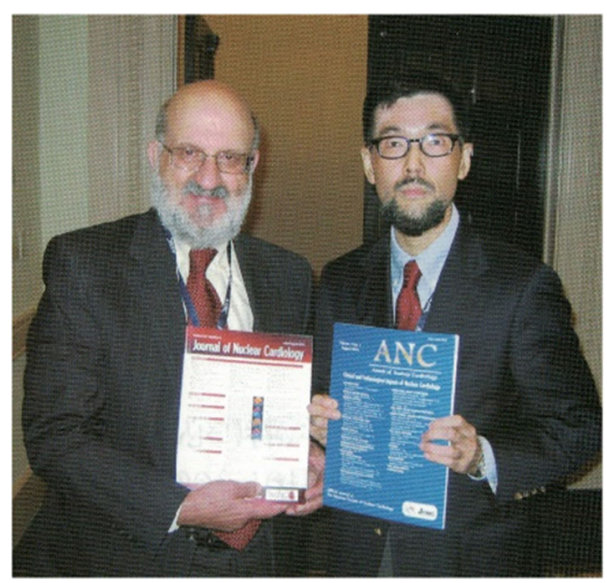

JNC Chief Editor and ANC Chief Editor at ASNC 2016 We had a chance to hold IAEA (International Atomic Energy Agency) Regional Workshop at Hokkaido University in autumn, 2019, which was attended by Drs Joao Vitola, Diana Paez, Marcelo Di Carli, and Jun Hatazawa (President of Japanese Society of Nuclear Medicine). Of course, Keiichiro played a major part in this workshop as one of the organizing committee members. Many students and young physicians from Asian countries attended the meeting to learn the clinical importance and recent developments in nuclear cardiology. The meeting was quite successful and achieved its objectives. In addition, many of us enjoyed the beautiful sceneries in the University Campus, and of 
course delicious meals at Sapporo during and after the meeting. Sadly, this was one of the last organized meetings where I met Keiichiro. hard worker fueled by passion, and has contributed so much in promoting nuclear cardiology, especially quantitative cardiac PET.

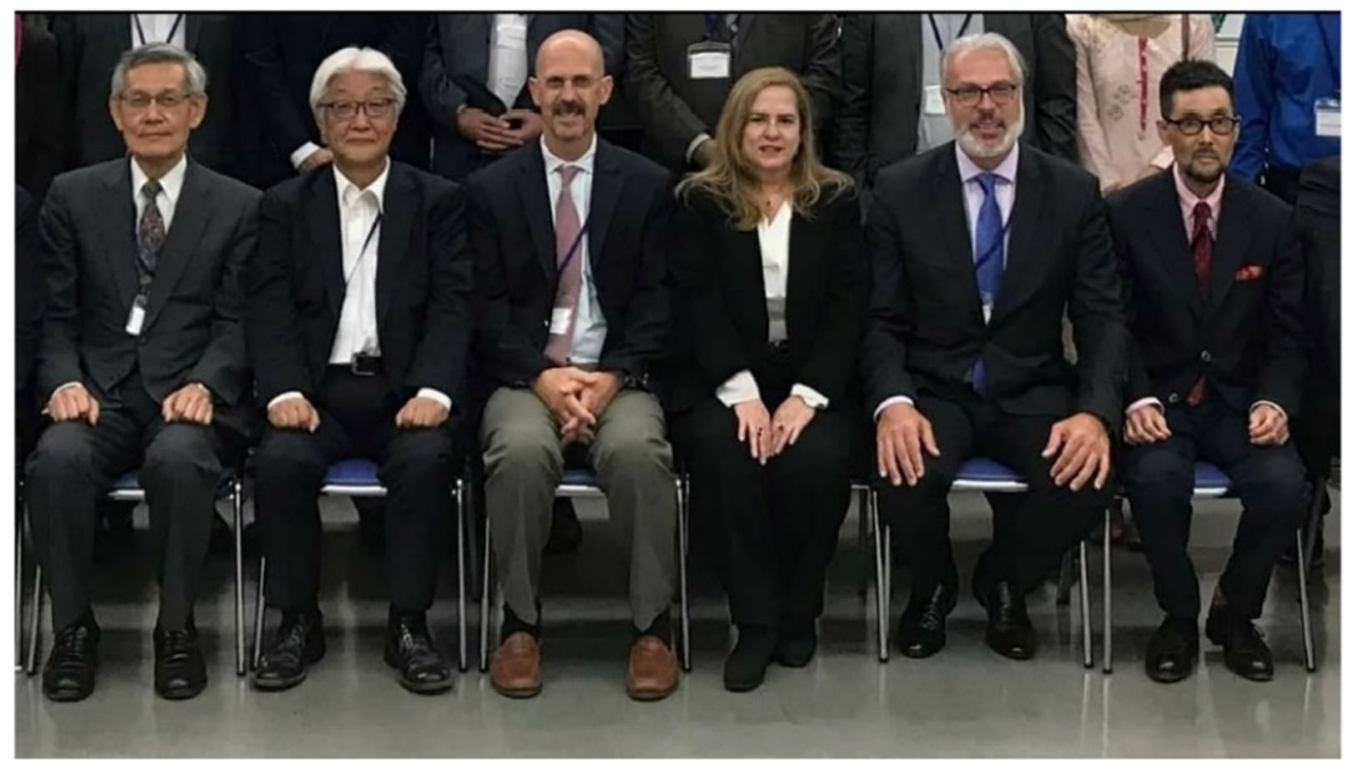

During IAEA Regional Workshop in Hokkaido University at Sapporo in 2019. From right: Keiichiro Yoshinaga, Joao Vitola, Diana Paez, Marcelo Di Carli, Jun Hatazawa, Nagara Tamaki

As many colleagues know, Keiichiro was always kind to everyone, and quite diplomatic. This is why he has had so many close international friends.

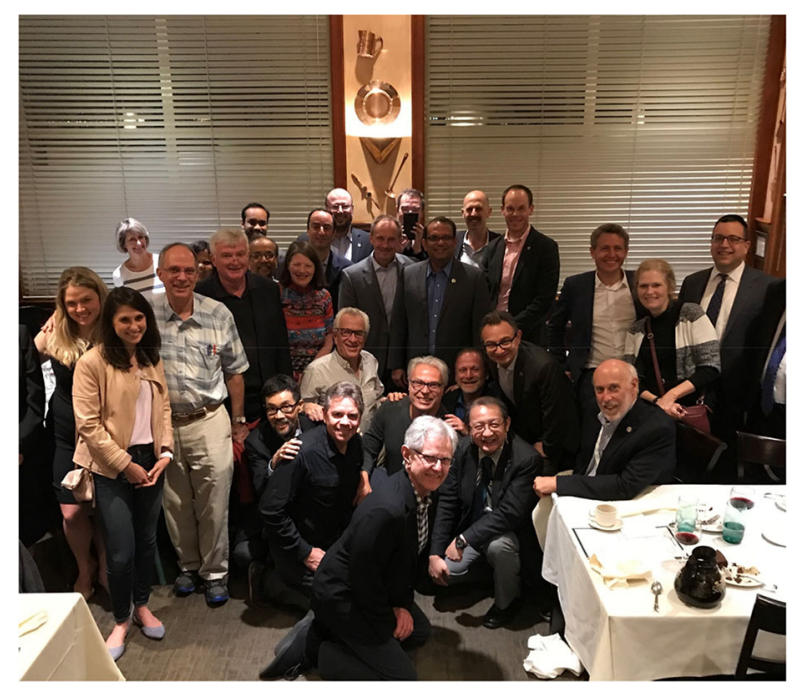

At dinner with friends at ASNC 2018 in San Francisco We are very happy to have had such a wonderful investigator in our department and to have worked together for some time. Keiichiro was a tremendously
The nuclear cardiology community has lost a brilliant scientist but more importantly an intimate friend. We are grateful for his vast contributions to science, medicine, and humanity. Our thoughts are with his family, friends, and loved ones he left behind.

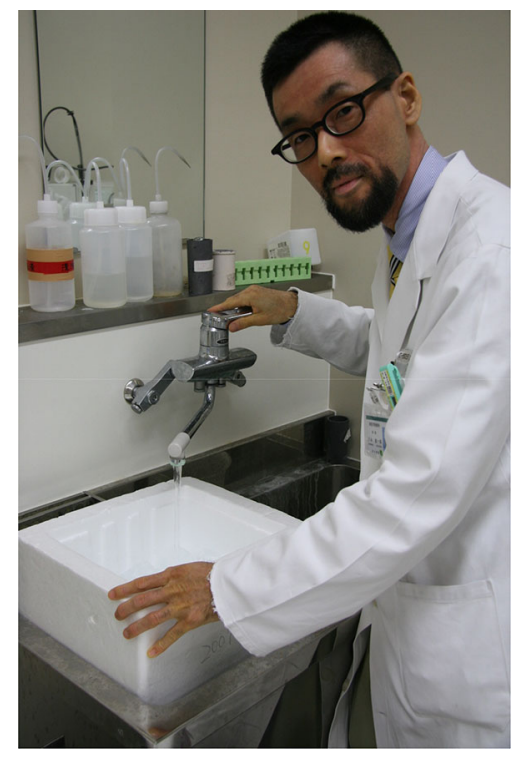

Keiichiro preparing for an experiment. 


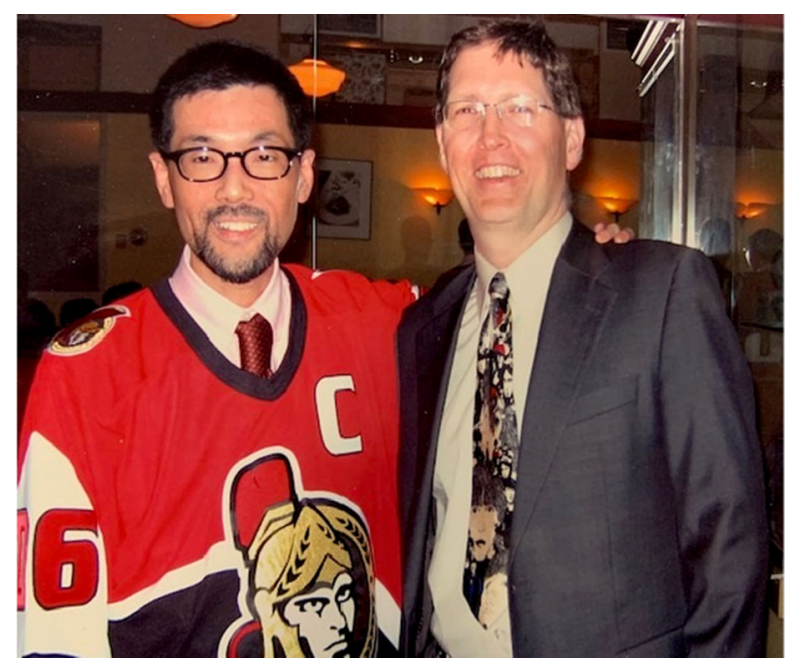

Publisher's Note Springer Nature remains neutral with regard to jurisdictional claims in published maps and institutional affiliations.

Keiichiro with Rob Beanlands at his fellowship graduation dinner in 2006. 